\title{
Um olhar sobre as prefeitas missioneiras: aprendizados, buscas e desafios femininos em cargos de gestão pública municipal
}

\author{
Luciana Scherer ${ }^{1}$ \\ Louise de Lira Roedel Botelho ${ }^{2}$ \\ Sandra Beatriz Fernandes ${ }^{3}$
}

\begin{abstract}
Resumo
A figura feminina tem passado por diferentes transformações, e a sua entrada no mercado de trabalho configura novas lideranças e formas de exercer poder, já que as mulheres passaram a ocupar cargos e funções até então desempenhadas por homens, trazendo um novo dinamismo às organizações públicas. A evolução nos modelos gerenciais públicos tem permitido que um número cada vez maior de mulheres ocupe espaços na política e na gerência de órgãos públicos, embora o número de mulheres atuantes na política ainda seja subrepresentado, se comparado ao número de homens. O objetivo principal deste trabalho é compreender a vida das mulheres prefeitas na Região das Missões do Estado do Rio Grande do Sul por meio das experiências vividas pelas investigadas no exercício de suas funções gerenciais e políticas no setor público. Como metodologia, utilizou-se o paradigma humanista de pesquisa, o qual a designa como um estudo qualitativo de cunho fenomenológico. Como procedimento de coleta de dados, foi utilizado o modelo de entrevista em profundidade de Seidman (1998). Foram entrevistadas as três prefeitas eleitas nos municípios missioneiros para a gestão 2013-2016. Entende-se que estudar o fenômeno de mulheres exercendo cargos eletivos configura-se como algo desafiador e necessário para a compreensão do próprio papel social que a mulher desempenha na atualidade. Espera-se que este estudo possa contribuir para a construção do conhecimento sobre a temática e que seja possível verificar traços de uma sociedade onde as mulheres lutam para conquistar seus espaços, suas posições e o reconhecimento, tanto na esfera pública como na privada.
\end{abstract}

Palavras-chave: Prefeitas. Gestão Pública. Liderança Feminina. Carreira Feminina.

\begin{abstract}
The female figure has undergone different transformations and their entry into the labor market configures new leaderships and forms of exercising power, since they have occupied positions and functions hitherto performed by men, bringing new dynamism to public organizations. The evolution in public management models has allowed an increasing number of women to occupy spaces in the politics and in the management of public organs, although the number of women in politics is still underrepresented when compared to the number of men. The main objective of this work is to understand the life of female mayores in the Missions Region of the state of Rio Grande do Sul through the experiences of those investigated in the exercise of their managerial and political functions in the public sector. As methodology, the humanistic paradigm of research was used, which designates it as a qualitative study of a phenomenological. As data collection procedure was used the model of interview in depth of Seidman (1998). The three women elected mayors were interviewed in the missionary municipalities for the management 2013-2016. It is understood that studying the phenomenon of women

\footnotetext{
${ }^{1}$ Doutoranda em Desenvolvimento Regional. Professora no Curso de Administração da Universidade Regional Integrada do Alto Uruguai e Missões (URI). lucianascherer@yahoo.com.br

2 Doutora em Engenharia e Gestão do Conhecimento. Professora da Universidade Federal da Fronteira Sul (UFFS). louisebotelho@uffs.edu.br

3 Doutora em Ciência do Solo. Professora no Programa de Pós-Graduação em Desenvolvimento da Universidade Regional do Noroeste do Rio Grande do Sul (UNIJUI).sandravf@unijui.edu.br
} 
exercising the position of elective is configured as something challenging and necessary for the understanding of the social role that women play today. It is hoped that this study can contribute to the construction of knowledge on the subject and that it is possible to verify traces of a society where women struggle to conquer their spaces, their positions and recognition in both the public and private spheres.

Keywords: Female Mayors. Public Management. Women's Leadership. Women's Career

\section{Introdução}

A trajetória da mulher na sociedade está cercada por diferentes transformações. Essas transformações geraram resultados no modo de vida feminino, sendo reflexos das construções sociais produzidas ao longo dos tempos. A sociedade, talvez para garantir a própria sobrevivência da espécie humana, agregou à mulher o papel de cuidadora no ambiente familiar, função essa que esteve associada por muito tempo à função materna. À medida que a sociedade vai se transformando, passando de agrária para industrial, a função social da mulher vai se adequando aos novos modelos. Surge a emancipação feminina, ou seja, uma busca pela igualdade de gêneros, nas relações da esfera do trabalho. Todo esse novo contexto acaba por modificar as formas como homens e mulheres condicionam suas competências a serviço da sociedade, e não apenas da família. A partir disso, as mulheres passam a pertencer à esfera pública do trabalho (FLETCHER, 2006). Como resultado, elas passam a adquirir direitos e autonomia financeira, além de engendrar no mundo formal do trabalho, que, durante muito tempo, foi percebido socialmente como um universo de predomínio masculino.

Com a entrada da mulher no mercado de trabalho, configuram-se também novas lideranças e novas formas de liderar. Elas passaram a ocupar cargos e funções até então desempenhadas exclusivamente por homens (CUNHA; SPANHOL, 2014), trazendo um novo dinamismo às organizações públicas (SOUZA; SIQUEIRA; BINOTTO, 2011). Entende-se que estudar o fenômeno das mulheres exercendo cargos eletivos em diferentes esferas públicas apresenta-se como algo desafiador e necessário para a compreensão do próprio papel social que a mulher desempenha na atualidade, já que ainda é possível verificar traços de uma sociedade onde as mulheres lutam para conquistar seus espaços, suas posições e o reconhecimento, tanto na esfera pública como privada.

Na gestão pública, talvez exerça um caso peculiar. Os processos de seleção, a influência política nas indicações, os problemas de descontinuidades derivados dos 
processos eleitorais trazem para esse cenário da participação feminina contornos ainda não suficientemente investigados. A evolução nos modelos gerenciais públicos tem permitido que um número cada vez maior de mulheres ocupe espaços na política e na gerência de órgãos públicos, tornando-as mais propensas a assumirem cargos de maior responsabilidade e exigência técnica por seus méritos, seja por indicação ou eleição, contudo, ainda muito aquém da participação masculina (SOUZA; SIQUEIRA; BINOTTO, 2011). Salienta-se que, embora o número de mulheres atuantes na política venha aumentando ao longo dos últimos anos, ainda é sub-representado, se comparado ao número de homens que exercem cargos políticos, podendo-se afirmar que o cenário político brasileiro ainda é marcado por traços de coronelismo masculino.

Referente à atuação em cargos políticos, segundo os dados do Tribunal Superior Eleitoral - TSE, embora as mulheres representassem cerca de $52 \%$ do eleitorado brasileiro em 2012, essa mesma proporção não é retratada na ocupação dos cargos políticos, já que 11,92\% do total de municípios brasileiros elegeram, para a gestão 2013-2016, mulheres para estarem à frente das respectivas prefeituras, ou seja, 664 prefeitas (TSE, 2016). Ainda em 2012, no estado do Rio Grande do Sul, foram eleitas 35 prefeitas, perfazendo um percentual de 7,04\%, valendo destacar que o poder ficou restrito a municípios com até 40 mil habitantes. Na Região das Missões ${ }^{4}$, composta por 25 municípios, foram eleitas três prefeitas - em Guarani das Missões, em São Paulo das Missões e em Sete de Setembro - ou seja, 7,5\% dos municípios missioneiros possuíam uma mulher à frente da prefeitura municipal na gestão 2013-2016 (TRE-RS, 2016).

O objetivo principal deste trabalho é compreender as trajetórias das mulheres que se tornaram prefeitas na Região das Missões, no estado do Rio Grande do Sul, por meio das experiências vividas por elas no exercício de suas funções gerenciais e políticas no setor público nesses três municípios supracitados. Salienta-se que o presente estudo não pretende evidenciar a realidade de todas as mulheres na política, tampouco abordará o seu processo de ascensão nesse setor, e, sim, concentrar-se em compreender a vida de algumas dessas

\footnotetext{
${ }^{4}$ Os municípios integrantes da Região das Missões do Rio Grande do Sul são Bossoroca, Caibaté, Cerro Largo, Dezesseis de Novembro, Entre-ljuís, Eugênio de Castro, Garruchos, Giruá, Guarani das Missões, Mato Queimado, Pirapó, Porto Xavier, Rolador, Roque Gonzales, Salvador das Missões, Santo Ângelo, Santo Antônio das Missões, São Luiz Gonzaga, São Miguel das Missões, São Nicolau, São Paulo das Missões, São Pedro do Butiá, Sete de Setembro, Ubiretama e Vitória das Missões (COREDE MISSÕES, 2012).
}

COLÓQUIO - Revista do Desenvolvimento Regional - Faccat - Taquara/RS - v. 15, n. 1, jan./jun. 2018 
mulheres que escolherem trilhar trajetórias profissionais no setor público municipal, para, a partir daí, apresentar alguns aspectos até então não discutidos.

O conhecimento sobre a participação da mulher na política é limitado pela dificuldade no processo de coleta de dados, os quais se apresentam parcos e dispersos, e muito raramente é observada a distinção entre homens e mulheres eleitos. Quando se recorre aos sites do Tribunal Regional Eleitoral do Rio Grande do Sul (TRE-RS) ou do Tribunal Superior Eleitoral (TSE), é possível encontrar algumas informações básicas, mas sempre bem mais ligadas ao perfil (nome, idade, formação, profissão, filiação partidária, etc.). Na academia, alguns ensaios teóricos buscam caracterizar estados específicos ou alguns contextos e perspectivas. Estudos um pouco mais aprofundados, baseados numa perspectiva ontológica, que busca conhecer as especificidades dessa relação mulher e cargo político, ainda parecem ser raros.

Este estudo está divido em três partes, além desta introdução e das considerações finais. A primeira apresenta os delineamentos metodológicos, as opções e posturas de pesquisa, bem como os instrumentos e as técnicas, como forma de conhecer a realidade a ser investigada. A segunda traz as discussões teórico-epistemológicas sobre as mulheres e sua representação política, por meio da apresentação de teorias e estudos já realizados acerca do tema. Na sequência, são apresentadas as realidades das prefeitas, segundo suas próprias percepções.

\section{Delineamentos metodológicos}

Este estudo utiliza o paradigma humanista de pesquisa (HUGHES, 1980), o qual o designa como um estudo qualitativo de cunho fenomenológico (ROESCH, 1996; MINAYO, 1994), já que se pretende compreender a trajetória das prefeitas com um olhar subjetivo da realidade (HUGHES, 1980).

Como procedimento de coleta de dados, foi utilizado o modelo de entrevista em profundidade de Seidman (1998), e foram entrevistadas três prefeitas de municípios pertencentes à Região das Missões, no Rio Grande do Sul. O instrumento utilizado foi a realização de entrevistas em profundidade, com o apoio de um questionário semiestruturado. Conforme Gil (1991), o questionário é um instrumento de coleta de dados 
constituído por uma série ordenada de perguntas, as quais devem ser respondidas por escrito e sem a presença do entrevistador. Para a validação do questionário, foi aplicado um piloto a uma mulher que já havia sido prefeita em outro município que não foi objeto deste estudo. Com base nas sugestões da respondente voluntária, ocorreram ajustes, e, a partir daí, o questionário final foi elaborado e dividido em três perspectivas norteadoras: a trajetória pessoal e profissional, a formação da identidade política e, por fim, as questões ligadas à carreira política.

A primeira perspectiva, a da trajetória pessoal e profissional, teve como objetivo buscar elementos sobre a vida da prefeita antes de ser prefeita: relatos sobre a infância, sobre a família, sobre a atuação pessoal e profissional até o momento em que se tornaram prefeitas. A segunda perspectiva observou a formação da identidade política das investigadas. Assim, buscou-se investigar os elementos condutores da formação da identidade política das prefeitas. Para tanto, utilizaram-se dois arcabouços teóricos principais: a teoria sobre o capital político, desenvolvida por Pierre Bourdieu, e a teoria sobre as prefeitas, de Eva Blay (2015), desenvolvida a partir da pesquisa seminal sobre as prefeitas baianas, sendo, posteriormente, corroborada por pesquisadoras como Barbosa (2010), em Rabay (2013 e Rodrigues (2016). Por último, a terceira perspectiva relativa à carreira tratou de conhecer alguns tópicos influenciadores da carreira feminina a partir de Bruschini (2011; 2000), Botelho (2006; 2008) e Moraes (2008), como a influência e a relação de marido e filhos(as) na carreira política das entrevistadas; a identificação das recompensas e dificuldades, mudanças na vida pessoal e profissional; aprendizagem e satisfação com a trajetória política e o modelo de gestão percebido.

A coleta de dados ocorreu no período de outubro a dezembro de 2016 , período em que as prefeitas já se encontram com uma experiência mínima próxima aos quatro anos de mandato. As entrevistas, que foram gravadas e posteriormente transcritas, foram realizadas com agendamento prévio e no gabinete das entrevistadas. Para que se analisassem os dados deste estudo, com base na gravação e transcrição das entrevistas, foram criadas categorias analíticas; dessa forma, pôde-se construir o texto final desta pesquisa.

Para a criação de categorias analíticas, utilizou-se o modelo de Miles e Huberman (1994); dessa forma, os resultados encontrados foram alocados em três momentos distintos: 
(a) Redução de dados: processo que permite a seleção, o foco, a simplificação, a abstração e a transformação dos dados coletados com o objetivo de obter algumas conclusões;

(b) Dispositivos visuais: são construções organizadas e condensadas de informações que ajudam no entendimento do estudo, proporcionando um encadeamento de ideias à medida que os dados vão sendo processados;

(c) Desenhos e verificações conclusivos: permite a organização de informação em séries diferentes, a criação de uma matriz de categorias, tabulação da frequência de diferentes eventos; dessa forma, as conclusões surgirão da manipulação de dados, a partir do momento em que se contrapõem os dados de entrevistados diferentes.

Ressalta-se que a postura metodológica deste estudo de caso foi realizá-lo com parcimônia, especialmente em relação às generalizações, ou seja, aqui a intenção metodológica é realmente conhecer os casos estudados, para, a partir daí, possibilitar a realização futura de estudos mais generalizáveis sobre o fenômeno em questão.

\section{Mulheres, liderança e carreira política}

A condição milenar da mulher na sociedade influencia a sua caminhada e o seu papel na atualidade. A crença quase natural em nossa sociedade de que o homem é superior à mulher acaba legitimando a discriminação (MORAES, 2004, p. 22). A história da mulher também é uma história de submissão ao homem, sendo uma construção social e cultural repleta de tensões e posicionamentos, onde as diferenças entre homens e mulheres são enfatizadas e observadas em diferentes campos, os quais se apresentam como esquemas de pensamento, de aplicação universal, e se registram como diferenças de natureza, inscritas na objetividade (BOURDIEU, 2011). As diferenças biológicas são transferidas para o campo social, sendo, assim, naturalizadas. Essas diferenças são percebidas culturalmente como algo normal, natural, inevitável, e, assim, legitimadas. Há, portanto, uma naturalização da construção social que legítima a histórica diferença e inferioridade da mulher perante o homem. 
Nas esferas de representação política da sociedade, esse cenário também se manifesta. Dados referentes à participação de mulheres em esferas do governo mostram que elas continuam sendo sub-representadas, indicando que a desigualdade no campo político também pode ser reflexo de uma desigualdade nos campos cultural, social e econômico.

Para contextualizar essa afirmação, bastam os dados acima, já apresentados na introdução deste trabalho, sobre a relação do percentual de mulheres eleitas, com os quais é possível inferir que o Brasil, nos indicadores de participação da mulher na política, ainda se encontra na retaguarda mundial no que se refere ao empoderamento feminino (ALVES, 2007). Portanto, parte-se do pressuposto de que estudar os cenários acerca desse fenômeno auxilia no conhecimento e na capacidade de atuação das mulheres na política.

Em estudos sobre a participação da mulher na política brasileira, é possível destacar quatro momentos e acontecimentos importantes. O primeiro é a conquista do voto feminino em 1932. O segundo é a emergência do movimento feminista da década de 70. O terceiro é a Constituição de 1988, e, por último, as cotas eleitorais para mulheres, que estabelecem os percentuais mínimos e máximos para cada sexo.

A luta pelo voto feminino no Brasil iniciou-se nas primeiras décadas do século XIX, quando as mulheres começaram a reclamar esse direito, contrapondo-se à mentalidade vigente na sociedade da época, que considerava a natureza feminina incompatível com as atividades políticas. Em 24 de fevereiro de 1932, o então presidente Getúlio Vargas promulga o Decreto № 21.076, aprovando o voto feminino às mulheres casadas, desde que tivessem autorização dos maridos, e a algumas solteiras ou viúvas, desde que tivessem renda própria, o direito de votar e serem eleitas. Assim, o Brasil tornou-se o quarto país no continente americano a garantir o, ainda restrito, direito de voto às mulheres.

O movimento feminista dos anos 1970, embora influenciado pelas experiências europeias e norte-americanas, foi marcado pela contestação à ordem política instituída no Brasil da época. Para as feministas, o poder é masculino, e seu objetivo final sempre foi a dominação das mulheres. Para Saffioti (1976), o movimento feminista brasileiro e os movimentos que se desenvolveram na mesma corrente ideológica, desempenharam funções de uma força social construtiva. O movimento feminista como um ato político pleiteou direitos igualitários, principalmente no cenário do trabalho. Dessa forma, a emergência do 
feminismo como movimento social criou o alicerce para a legitimação da condição feminina (BRUSCHINI, 2000).

Em relação à Constituição de 1988, colocada como o terceiro momento importante para a inserção das mulheres na política nacional, ela assegurou a igualdade de direitos e obrigações para mulheres e homens e a igualdade na sociedade conjugal, bem como a criação de novos direitos, como planejamento familiar, proteção contra a violência, no âmbito das relações familiares; ampliação da noção de família; não discriminação dos filhos havidos fora do casamento; licença paternidade; creches e pré-escolas; proteção ao mercado de trabalho da mulher, dentre outros.

E no quarto momento sobre as cotas eleitorais para mulheres, podem-se destacar dois acontecimentos, a Lei 9100/95 e a Lei 9504/97. A primeira lei prescrevia a exigência do registro de, no mínimo, $20 \%$ de candidaturas femininas por cada partido ou coligação. No mesmo ano, a então deputada federal Marta Suplicy, apoiada por mais 26 deputadas, elaborou o Projeto de Lei 783, que culminou na revogação do art. 92 do Código Eleitoral, aumentando o percentual mínimo para 30\%, entrando em vigor a segunda Lei acima citada (VAZ, 2008).

É importante ressaltar que a Lei 9504/97 não estabelece a obrigatoriedade de preenchimento das vagas para mulheres e também não determina ao partido um ônus pelo não preenchimento das cotas, facilitando o lançamento de candidatas sem o real apoio do partido ou com chances significativas. Para Blay (2002), houve pouco debate com a sociedade para a implantação da Lei, especialmente com o movimento de mulheres, já que não ocorreram debates em plenário, além de serem rejeitadas propostas que criariam melhores condições de competição por parte das mulheres. A rejeição dessas propostas deixou lacunas, não contemplando as reivindicações que poderiam fortalecer as mulheres para a competição política. Porém, tornar mais visível a questão da pouca representação política da mulher é um ponto positivo da Lei (BRABO, 2003), pois trouxe à tona muitas reflexões, discussões e questionamentos sobre a não participação e até mesmo a exclusão da mulher nas esferas de poder.

Mesmo com uma participação ainda pequena, é importante, nos estudos sobre a atuação feminina nos cenários político, social, cultural, considerar o papel de agentes políticos femininos, ligando essas percepções ao universo feminino e ao desenvolvimento 
das regiões. Partindo da análise dos dados eleitorais e das discussões incitadas, sente-se a necessidade de compreender as mulheres prefeitas enquanto protagonistas em um processo de empoderamento social e político.

Blay (2015), em seu estudo sobre as prefeitas no Brasil, concluiu que algumas características e situações aglutinam-se mutuamente, ou seja, algumas características, como relações familiares, personalidades e forma de ingresso na vida política, definiram, para essa autora, a possibilidade de uma classificação geral baseada em três categorias: a Prefeita Coronel, a Prefeita Esposa e a Prefeita por Iniciativa Própria.

A Prefeita Coronel é aquela que, principalmente - mas não necessariamente - na ausência de um homem, assume a liderança da família, a direção dos negócios, do grupo político e da clientela, por meio da utilização de velhas práticas clientelísticas, como as do "mandonismo". Em sua maioria pertencente às oligarquias locais, assim como os homens, é socializada para assumir a direção política do grupo familiar quando se faz necessário. A Prefeita Coronel assume a posição de líder na família, podendo essa posição ser obtida perante a sua família de origem, como a estabelecida pelo casamento. Ao incorporarem essa liderança, é possível que essas prefeitas utilizem alguns traços comportamentais típicos masculinos e, muitas vezes, precisem convencer seus pares sobre a sua capacidade. Assim, a luta pela liderança começa em casa, no seu ambiente familiar.

A Prefeita Esposa é aquela que assume as funções do marido na política, em decorrência de algum impedimento de ordem legal, ou com o objetivo de continuar no controle do poder. Ainda, a imagem adquirida como "esposa de político", por meio de atividades sociais ou assistencialistas, garante a constituição de uma base eleitoral que é sabiamente aproveitada. Assim, exercer o cargo é, em verdade, uma delegação do marido. Pode ocorrer que, quando é necessário tomar uma decisão importante para o município, consulte o marido (BLAY, 2015). Por fim, a "prefeita por iniciativa própria" seria aquela que, por suas próprias convicções e liderança, construiu capital político suficiente para se eleger. Desse modo, esse terceiro grupo se distinguiria dos dois primeiros.

Além da tipologia apresentada por Blay (2015), outro importante conceito emerge na discussão deste trabalho, o de capital político desenvolvido por Pierre Bourdieu. Esse conceito basicamente indica o reconhecimento social que permite que alguns indivíduos, 
mais do que outros, sejam aceitos como atores políticos e, portanto, capazes de agir politicamente.

O capital político é uma forma de capital simbólico, cuja eficácia está ligada à universalidade do reconhecimento que ele recebe, ou seja, ele permite alguma autoridade a alguém. O capital político é tido, então, como uma espécie de capital simbólico: o reconhecimento da legitimidade daquele indivíduo para agir na política (BOURDIEU, 1980). Afirma ainda que o capital político

\footnotetext{
assegura a seus detentores uma forma de apropriação privada de bens e serviços públicos [...] vemos então que o capital social de tipo político que se adquire nos aparelhos de sindicatos e dos partidos transmite-se através de redes de relações familiares que levam à constituição de verdadeiras dinastias políticas (BOURDIEU; 1996, p. 30).
}

O que muda, se compararmos os tipos de prefeita, segundo a classificação proposta, é a forma como estas constroem e fazem legitimar o seu capital político, ora pela atuação da família - na ausência de um homem para comandar os negócios e a política -, ora pela atuação como esposa de um político, ou até mesmo pela sua atuação de forma independente na sociedade e nas esferas políticas. Nota-se que a noção de dinastia política colocada acima por Bourdieu parece bastante ligada à forma de construção de capital político das prefeitas coronel e das prefeitas esposa, as quais já possuem um capital simbólico herdado pela atuação da família e/ou do marido.

Bourdieu (1986) elabora o desafio de desenvolver a questão da importante conexão entre grupo e indivíduo representante e aborda a necessidade de reflexão sobre o poder que os líderes políticos possuem ao agir e ao comunicar-se em nome dos representados. Um líder deve democratizar seu interesse próprio, de modo que pareça ser o interesse dos liderados, e, para isso, existe um conjunto de técnicas de oratória, de construção textual e de aparência. Através dos aspectos quantitativos da participação política feminina, é possível encontrar respostas sobre os mecanismos de dominação que, ainda hoje, mantêm a baixa participação das mulheres nas instâncias representativas da política e do poder (BARBOSA; CAVALCANTI, 2010).

Prevalece ainda na sociedade uma visão reducionista, que adequa as "vontades femininas" à falta de interesse e envolvimento com os assuntos políticos, ou até mesmo ao cumprimento obrigatório por parte dos partidos políticos das leis de cotas para mulheres na 
política. Todo esse discurso já é conhecido pelos pesquisadores, mas constatar o fato não é relevante, é necessário buscar as causas, conhecer a trajetória, o perfil, as aprendizagens e os desafios e superações vividos pelas mulheres que desenharam suas carreiras profissionais na vida pública e se tornaram prefeitas em seus municípios. Estudar essas mulheres é conhecer e reconhecer que ser mulher em um ambiente tradicionalmente marcado pela cultura masculina de poder pode se mostrar como um cenário de intensos desafios e aprendizagens.

\section{As prefeitas missioneiras: aprendizados, buscas e desafios}

O primeiro aspecto que pode ser destacado entre as prefeitas pesquisadas diz respeito à classificação proposta por Blay (2015). Embora classificações possam demonstrar alguma arbitrariedade e, portanto, desconsiderar aspectos importantes, nos discursos de apresentação e autodescrição das prefeitas, é possível identificar as características dominantes que permitem utilizar a proposição da autora. Nenhuma pode ser considerada Prefeita Coronel - aquela que assume os negócios e a posição política da família, na ausência de uma figura masculina, pois todas são casadas, e o marido aparece como uma figura importante e atuante em suas vidas. Uma foi identificada como Prefeita Esposa - aquela que assume o desafio de um mandato como prefeita em função de algum impedimento do marido: o marido já havia sido vice-prefeito, prefeito e não conseguiu reeleger-se, e, depois de 4 anos, a esposa surge como um nome forte para candidatar-se. Duas foram identificadas como Prefeita por Iniciativa Própria - aquela que não possui tradição de ocupação de cargo político nem na família de origem, nem na família de matrimônio, e identifica-se como a decisão de candidatar-se à prefeita como sua própria:

\footnotetext{
Meu pai era ligado a partido político, mas nunca exerceu cargo. Era uma liderança comunitária. Meu marido não tinha ligação nenhuma com política. Acho difícil identificar qual foi a maior influência, mas acho que a decisão partiu de mim mesma, da vontade de fazer algo bom, mas em conversa com a minha família (PREFEITA DE GUARANI DAS MISSÕES - RS).
}

(Continua) 


\begin{abstract}
Meu pai não era ligado à política, mas meu marido foi vice-prefeito e prefeito no município, e foi um bom prefeito, e eu sempre o acompanhei bastante, como primeira-dama e como presidente do partido. Depois de ele ser prefeito, meu nome começou a circular como uma possibilidade nas eleições de 2012. Eu nunca havia pensado em ser prefeita, mas o nome foi surgindo na comunidade, e o partido convidou, e, então, em decisão com o meu marido, aceitei! (PREFEITA DE SÃO PAULO DAS MISSÕES - RS).

Nem meu pai, nem meu marido eram políticos. Pode-se dizer que a decisão partiu de mim mesma. Embora meu marido tenha se filiado ao partido junto comigo, a decisão de ser prefeita surgiu após ter sido Secretária de Saúde, vereadora mais votada e, depois disso, resolvi encarar - e fui eleita para dois mandatos seguidos (PREFEITA DE SETE DE SETEMBRO - RS).
\end{abstract}

Dentre as prefeitas entrevistadas, todas apresentavam experiência política anterior à ocupação do cargo de prefeita, ou como primeira-dama, ou como secretária no município, ou como presidente de partido político no município, ou como vereadora - duas haviam sido vereadoras em seus municípios. A prefeita de Guarani das Missões-RS fora vereadora por três mandatos seguidos (2000 a 2012), e a prefeita de Sete de Setembro-RS, por um mandato (2004 a 2008), sendo essa última prefeita em dois mandatos seguidos (2009 2016). Pode-se dizer que esses papéis desempenhados anteriormente - de primeira-dama, de secretária, de presidente de partido político, ou de vereadora, na maioria das vezes, serviram de "treinamento" para a fala pública, para a ocupação do espaço público e dos palanques, bem como para a própria gestão, as articulações eleitorais e o "corpo a corpo" com o eleitorado. Esse fato está ligado à construção do capital simbólico e do capital político proposto por Bordieu (1980), no sentido da importância de construção de uma legitimidade quanto pessoa apta e reconhecida para agir em nome dos representados.

Ainda no sentido de duas delas terem ocupado cargos de vereadoras, há um destaque para a Lei das Cotas, pois elas foram convidadas a concorrer no legislativo em função da necessidade de os partidos apresentarem os percentuais de $30 \%$ de candidaturas de mulheres. A decorrência disso é que, de lideranças locais, surgiram líderes no legislativo local e, posteriormente, no executivo. Todas concordaram que ações afirmativas, como a Lei de Cotas, são importantes para o surgimento das lideranças femininas. Mesmo que num primeiro momento possa parecer "obrigação" para a mulher candidatar-se, para o preenchimento das vagas determinadas pela referida Lei, aos poucos, vão se formando lideranças femininas. A Prefeita de Sete de Setembro-RS deixa claro que "Temos que 
destacar a importância da Lei das Cotas, pois foi muito em função dela que eu concorri para vereadora, e, a partir disso, construí meu nome para ser prefeita".

As prefeitas entrevistadas demonstraram personalidades distintas, mas características bastante comuns: firmeza, alegria, apego à família, laços com a comunidade e uma preocupação bastante especial em fazer "o melhor, o bem, melhorar a vida das pessoas, contribuir para o município". Ao serem questionadas sobre quais os sentimentos que impulsionaram a entrada dessas mulheres na vida política, a comunidade aparece como o elemento mais importante para essa escolha de vida:

\begin{abstract}
A comunidade. 'Servir à comunidade', fazer melhor. Eu quis fazer muitas coisas boas, muitas melhorias para a população. E isso me fez entrar na política e a ser prefeita. Eu sempre acreditei que pela política séria podemos mudar e melhorar uma cidade. E esse sentimento me acompanha sempre (PREFEITA DE GUARANI DAS MISSÕES - RS).
\end{abstract}

Foi um sentimento de dever, de contribuição. Queria contribuir para o município. Pensei, junto com o marido, que, já que tínhamos escolhido o município e que não queríamos dali sair, então talvez ser prefeita, para ajudar a comunidade e fazer algo, seria uma boa missão. Só reclamar não ajuda, tem que tentar fazer algo que deixe a marca de contribuição para o município (PREFEITA DE SÃO PAULO DAS MISSÕES - RS).

Sempre pensando em fazer algo bom para a comunidade. Isso como funcionaria pública, como vereadora, como prefeita. Eu tenho muito orgulho das conquistas, do atendimento em saúde que consigo oferecer à população, acho que isso faz diferença na vida das pessoas (PREFEITA DE SETE DE SETEMBRO - RS).

Existe, nos discursos, um sentimento de "responsabilidade" e o reconhecimento da necessidade de honrar os votos e a confiança dos eleitores, conduzindo à ideia de uma conquista, de uma importância de ter "chegado lá". O pioneirismo em relação ao papel de uma mulher à frente da prefeitura dos seus municípios também é bastante mencionado, sendo que a maneira de expor a trajetória política inaugural de mulheres nos seus municípios, sugere algo de dimensão afirmativa da presença feminina em espaços de representação: "Ser a 'primeira' prefeita do município é um orgulho muito grande" (PREFEITA DE GUARANI DAS MISSÕES - RS); “Fui a primeira prefeita, e única, dentre todos os prefeitos em mais de 50 anos, a conquistar uma reeleição" (PREFEITA DE SÃO PAULO DAS MISSÕES - RS); “Fui a 'primeira' prefeita de toda a região das Missões, e também a 'única' reeleita" (PREFEITA DE SETE DE SETEMBRO - RS). 
Sobre a relação família $\mathrm{x}$ política, outro elemento bastante comum, a importância da família e do apoio do marido:

A minha família tem influência total na minha trajetória. Minha família é tudo. Afinal, é de lá que a gente sai para trabalhar e para lá que a gente volta, então, não tem como não considerar a família como a base de tudo que a gente vai fazer. A minha família sempre foi central nas minhas decisões, e meu marido é um apoio importante (PREFEITA DE GUARANI DAS MISSÕES - RS).

Teve muita influência do marido, e as filhas apoiam muito. Meu marido me acompanha nos compromissos, conversamos muito sobre tudo. Tem muito apoio da família, embora eu acho que a família é o que fica mais de lado, mais sem atenção, por mais que a gente tente dar atenção sempre que possível (PREFEITA DE SÃO PAULO DAS MISSÕES - RS).

Meu marido sempre me apoiou, e isso, para mim, é fundamental e muito importante. Ele não gosta de política, mas sempre esteve comigo, e minhas filhas se criaram no meio da política, ou em campanha, ou com a mãe secretária municipal, ou vereadora, ou como prefeita; enfim, isso realmente faz parte da rotina da família (PREFEITA DE SETE DE SETEMBRO - RS).

As prefeitas costumam reforçar certos estereótipos femininos, como a sensibilidade, aspectos de vaidade e um "jeitinho feminino", que não necessariamente está bem definido, mas que parece ser bem entendido no senso comum. A utilização dos chamados "atributos femininos" no campo político tem adquirido aspectos mutáveis. Pode significar barreiras, mas também pode, dependendo da situação, significar capacidade e interesse de quem os utiliza, agregando sentidos positivos, valorizando uma candidatura e compondo parte do capital simbólico de uma personalidade pública. Segundo a Prefeita de Guarani das Missões - RS, "A mulher já tem essa sensibilidade que já vem da natureza". Para a Prefeita de Sete de Setembro - RS, "O fato de ser mulher facilita esse contato com o povo". Para a Prefeita São Paulo das Missões - RS, "Talvez por ser mulher, e por ser mais sensível, os ataques não são tão fortes".

Ainda sobre os atributos femininos, especificamente no quesito vaidade: "Às vezes, minha filha diz: Mãe, vamos arrumar esse cabelo. Aí vou para o salão de beleza com ela, e já temos um momento juntas, mãe e filha" (PREFEITA DE GUARANI DAS MISSÕES - RS). Ainda é possível reconhecer alguns elementos da teoria de Bordieu sobre as técnicas a serem utilizadas por um líder, ao relacionar-se com os liderados, quando a Prefeita de Sete de Setembro - RS - fala sobre a importância de manter uma boa aparência e também sobre como ela deve saber dirigir-se a diferentes grupos em diferentes espaços: 
Eu reservo um tempinho rápido no salão para manter o jeito feminino. Nada de exagero, mas um pouco para me arrumar, para estar bem apresentada. Meu salto fica aqui no gabinete, eu trabalho de salto alto sempre. Mas, se vou para uma obra, coloco uma botina. Então eu sempre cuido disto: saber onde se está e estar adaptada ao espaço e ao público.

Ressaltam que a prefeita tem uma rotina que lhe exige um desdobramento entre casa e prefeitura, ou seja, uma relação entre o público e o privado. Em várias falas, as prefeitas fizeram referência ao trabalho doméstico e à educação dos filhos:

Eu tenho a assessoria de uma funcionária em casa, e minha filha maior também ajuda, principalmente quando ela está de férias. A casa não para, sempre tem algo para fazer. No meu dia a dia, eu preciso levar e buscar minha filha pequena na escolinha, e sempre tem uma tarefinha, um teminha, algo para ajudar a pequena (PREFEITA DE GUARANI DAS MISSÕES - RS).

Eu levanto muito cedo, sou a primeira a chegar e a última a sair. Tenho uma funcionária em casa que me ajuda com as tarefas, prepara as coisas para mim. Eu sempre anoto tudo que vou fazer no dia, e tento ir em tudo, tudo mesmo a que me convidam. E sempre tento levar meu marido comigo. As minhas filhas já não estão todo o dia comigo, então as tarefas da casa são mais das minhas coisas e do meu marido. Mas a casa também faz parte da rotina e da preocupação da gente (PREFEITA DE SÃO PAULO DAS MISSÕES - RS).

Eu tenho duas meninas, e até pouco tempo, eu tinha uma assessoria doméstica. Então eu me dei conta de que, para ensinar minhas filhas a ter uma responsabilidade com a casa, a melhor forma era eu assumir isso e dividir a tarefa com a família. Eu dispensei a minha funcionária doméstica, para tentar formar minhas filhas, atribuindo a todos a responsabilidade de ajudar na casa. Eu sempre achei que, se tivesse alguém para fazer isso por mim, na minha casa, as minhas filhas poderiam pensar que não precisam ter responsabilidade na casa. Essa foi a maneira que eu encontrei para garantir essa responsabilidade às minhas filhas. Hoje, as tarefas da casa são comigo e com as minhas filhas. As minhas filhas são meu orgulho, estudam bastante, têm notas ótimas e me ajudam em casa (PREFEITA DE SETE DE SETEMBRO - RS).

As experiências são permeadas por recompensas, dificuldades e aprendizados, e, o caso da experiência de ser prefeita não é diferente, sendo que cada entrevistada pôde identificar esses elementos em suas atuações. As recompensas do cargo mencionadas transitam entre as realizações da gestão, o sentimento que as pessoas lhes destinam e também o orgulho de ser a mulher à frente da prefeitura de seus municípios. Para aquela classificada como Prefeita Esposa, além das realizações da gestão, há uma ênfase significativa ao sentimento que as pessoas lhe destinam: "A dedicação reconhecida" (PREFEITA DE SÃO PAULO DAS MISSÕES - RS). Tudo isso combinado com o grande orgulho 
que se identifica em suas falas, o de ser uma mulher à frente da prefeitura. Já as classificadas como Prefeita por Iniciativa Própria têm em comum o destaque para as realizações do governo, não as reconhecendo, necessariamente, pelo fato de ser mulher:

As minhas recompensas são as coisas que eu consegui construir, comprar, melhorar para a cidade. As obras, os asfaltamentos, as máquinas, os carros e implementos agrícolas. Uma coisa que me faz feliz é a ajuda que pude dar aos agricultores com os maquinários adquiridos. Essas recompensas estão bem ligadas à gestão, e não ao fato de ser mulher, acho que estão na dimensão da gestora pública. Enfim, a maior recompensa, com certeza, é o serviço à comunidade (PREFEITA DE GUARANI DAS MISSÕES - RS).

Eu tinha muita preocupação com as pessoas indo embora do município, então tentamos fortalecer o agricultor. Uma grande recompensa foi ver o fortalecimento da economia do município por meio de ações voltadas para o agricultor. Incentivamos a atividade da suinocultura; trabalhamos as estradas, para dar trafegabilidade ao agricultor; adquirimos máquinas, para facilitar, por meio de ações cooperadas, o dia a dia dos agricultores do município. Outra recompensa é a instalação de atendimento em clínica médica. Eu sou muito orgulhosa do atendimento de saúde que o município presta aos moradores (PREFEITA DE SETE DE SETEMBRO - RS).

\section{As dificuldades destacadas foram:}

As dificuldades têm origem na falta de recursos e na grande burocracia exigida para tudo que se faz na prefeitura. Muitas vezes, a gente faz um planejamento e, quando recebe o recurso, vem bem menos do que o esperado, e isso, para um município pequeno, é muito difícil, pois não conseguimos cumprir o planejado por falta de recursos (PREFEITA DE GUARANI DAS MISSÕES - RS).

As dificuldades é que a gente não consegue realizar tudo que quer. A gente quer sempre fazer mais, mas não tem recurso suficiente, há as normas que devem ser seguidas à risca, e isso, muitas vezes, deixa a gente mais limitada. Eu acho também, que, para mim, as viagens são uma dificuldade. Eu não gosto muito de ir para Porto Alegre ou para Brasília. Até vou, mas, para mim, é uma das dificuldades. E outra coisa que tenho que fazer muito e que ainda me deixa nervosa: falar em público, dar entrevista para rádio e TV. A gente faz, mas, para mim, é uma dificuldade (PREFEITA DE SÃO PAULO DAS MISSÕES- RS).

A ingratidão das pessoas. Isso me magoa. Eu sempre tento ajudar tanto, e há tantos casos em que as pessoas não reconhecem, não valorizam. Mas acho que isso não tem relação com o fato de eu ser mulher, mas com o fato de que as pessoas querem sempre mais e não se colocam no lugar do outro. Eu não acho que isso ocorra por eu ser mulher, mas pelo fato de que as pessoas esperam mesmo sempre mais (PREFEITA DE SETE DE SETEMBRO - RS).

Ao serem questionadas sobre as dificuldades pelo fato de serem mulheres, a Prefeita de Guarani das Missões - RS - foi aquela que destacou com maior ênfase: 


\begin{abstract}
Acho que nenhuma recompensa tem relação com o fato de eu ser mulher, mas muitas dificuldades têm relação com esse fato. Durante todo o mandato, eu sentia, no dia a dia, que muitos homens não se sentiam confortáveis por ter uma mulher na prefeitura, ainda mais de um partido como o meu. Eu sentia que muitos achavam que, por ser mulher, a autoridade não era a mesma. Infelizmente, uma prefeita mulher estava muito fora do que a sociedade machista aceitava para o município. E eu realmente senti isso, já na campanha, e também durante os anos, como prefeita.
\end{abstract}

Ao serem questionadas sobre o estilo de gestão de cada uma, se viam-se com uma gestora centralizadora, participativa ou democrática, as respostas convergiram para um estilo participativo. As reuniões semanais de acompanhamento das ações da equipe foram colocadas como estratégia importante para a relação da prefeita com a equipe de secretários e demais funcionários: "Não sou centralizadora, eu me acho bem participativa. Tento tomar a decisão em conjunto, para poder defender a ação em conjunto" (PREFEITA DE GUARANI DAS MISSÕES - RS); "Eu consigo delegar, me acho participativa... Faço uma reunião semanal com todos os secretários, e marcamos uma data para eles me apresentarem a solução para todas as tarefa a serem cumpridas" (PREFEITA DE SÃO PAULO DAS MISSÕES - RS); “Eu ouço muito, aprecio muito as sugestões, e meu gabinete sempre está aberto para todo e qualquer funcionário. Não, definitivamente não sou centralizadora" (PREFEITA DE SETE DE SETEMBRO - RS).

Sobre a trajetória política, se estão satisfeitas e se mudariam algo, se pudessem "voltar atrás", as prefeitas mostram-se bastante satisfeitas: "Estou muito satisfeita. Eu faria tudo novamente. Acho que só me arrependo do que deixei de fazer, mas com o que eu fiz, eu gosto e estou satisfeita” (PREFEITA DE SÃO PAULO DAS MISSÕES - RS); “Eu faria tudo de novo. Valeu a pena"! (PREFEITA DE SETE DE SETEMBRO - RS). As considerações sobre alguma conduta diferente, ao longo da atuação como prefeita, foram bastante específicas quanto às suas relações com a equipe de colaboradores:

\footnotetext{
De forma geral, eu estou satisfeita. Fiz tudo com honestidade, com as melhores intenções. Eu tinha muitos planos e sonhos para o município. Em relação a voltar atrás, hoje eu me acho mais preparada para montar uma equipe qualificada, leal e de confiança, que esteja alinhada com o que eu gostaria de fazer. Acho que a equipe de funcionários públicos, seja do quadro efetivo ou dos cargos comissionados, tem um papel fundamental no sucesso da gestão (PREFEITA DE GUARANI DAS MISSÕES - RS).
}

Ao serem questionadas sobre o aprendizado adquirido, nas falas das prefeitas foi possível observar duas menções principais: questões ligadas à gestão pública e ao 
aprendizado pessoal: “Aprendi muito sobre gestão pública, sobre gestão de equipe. E quero continuar estudando, quero voltar aos estudos sobre essa e outras temáticas. O dia a dia no setor público ensina muito. A equipe influencia muito" (PREFEITA DE GUARANI DAS MISSÕES - RS). "Aprendi a compreender as pessoas" (PREFEITA DE SÃO PAULO DAS MISSÕES - RS); "Aprendi a ter mais equilíbrio emocional. Eu aprendi que não adianta ter ansiedade, que eu não vou conseguir resolver todos os problemas do meu município. Tudo ao seu tempo" (PREFEITA DE SETE DE SETEMBRO - RS).

Embora no instrumento de pesquisa não tenha se destacado nenhuma questão em relação ao machismo, esse foi um aspecto bastante mencionado pelas prefeitas, em especial para as duas classificadas como Prefeitas por Iniciativa Própria:

\footnotetext{
Na campanha, muitos diziam que eu não tinha chance porque eu era mulher. A nossa sociedade é machista, uma cidade pequena, de interior, e não podemos dizer que não sofremos com o machismo. Há, sim. Mas eu quero ver onde está escrito que a mulher tem que ficar em casa, cuidando da casa e dos filhos, e que o homem tem que assumir cargos públicos. Quem disse isso? (PREFEITA DE GUARANI DAS MISSÕES - RS).

A campanha foi bem difícil, o tempo todo eu ouvia que eu não tinha capacidade, que era mulher, e teve até música da oposição rodando em carro de som que abordava que lugar de mulher não é na prefeitura. Teve uma coisa muito machista, era feio ouvir aquilo. Mas acho que foi aí mesmo que as mulheres se revoltaram e votaram em mim, acho que deu o efeito contrário (PREFEITA DE SETE DE SETEMBRO - RS).
}

Outro elemento importante, ainda em relação ao machismo, é que, apesar de já possuírem certa experiência política, aparece o receio de serem atacadas em sua vida privada, sendo presente em suas falas a "necessidade de se resguardar, ter retidão e postura". Esse aspecto foi fortemente mencionado, em especial pelas Prefeitas por Iniciativa Própria, mais do que pela Prefeita Esposa, motivado pelo fato de surgirem alguns comentários maldosos, por meio dos quais pessoas da comunidade abordavam os maridos, em tons maliciosos, angústias que apareceram nos seus comentários: 
Algumas vezes, chegavam a falar para o meu marido: A tua mulher chegou sozinha com o fulano na reunião, chegaram os dois no mesmo carro, e só os dois - mas o fulano era secretário na prefeitura. Às vezes falavam sobre eu chegar, ou sair sozinha dos lugares, com intenção de deixar algo subentendido... O machismo também está nesses comentários maldosos (PREFEITA DE GUARANI DAS MISSÕES).

É difícil, porque tu tens que ir a muitos lugares, e o teu marido não está sempre contigo, pois ele tem o trabalho dele, e aí algumas pessoas acabam usando isso para te difamar. A forma como encontrei para evitar um pouco isso é deslocar um parente, que era funcionário da prefeitura, para ser meu motorista e me acompanhar. Mas, mesmo assim, falavam. A minha resposta para isso sempre foi: Mas e daí? Isso não é função da prefeita, estar em lugares, acompanhar obras e participar de reuniões e eventos no município? (PREFEITA DE SETE DE SETEMBRO - RS).

Por último, um aspecto bastante importante que foi colocado pelas prefeitas em suas falas foi a relação da eleitora mulher com a candidata mulher, e até mesmo dos eleitores de forma geral com uma prefeita mulher. De forma geral, essas prefeitas acreditam que o baixo número de mulheres, tanto no poder executivo como no legislativo das prefeituras, diz respeito ao fato de delas próprias não reconhecerem as mulheres como uma boa opção de autoridade. Esse argumento baseou-se no fato de que a maioria da população é de mulheres, então, se as eleitoras mulheres reconhecem as próprias mulheres, teríamos muito mais representantes femininas na política: "Se a gente for analisar, as mulheres não valorizam as mulheres. Olhe os votos. A maioria dos eleitores são mulheres, e quantas prefeitas e vereadoras temos? As mulheres acham que os homens são mais capazes" (PREFEITA DE GUARANI DAS MISSÕES - RS).

\section{Considerações finais}

Ao observar as mudanças políticas e culturais, mesmo que superficialmente, é possível considerar, nas últimas décadas, uma tendência, ainda que pouco expressiva, de inserção das mulheres nas disputas eleitorais. A Lei 9504/97, cotidianamente conhecida como "Lei das Cotas", que estabelece hoje um percentual mínimo de $30 \%$ de candidaturas femininas nas nominatas das coligações, parece ser um mecanismo afirmativo de inserção das mulheres na política. Embora ainda haja críticas sobre sua efetividade, é possível considerar que, mesmo que de forma lenta e gradual, esse instrumento legislativo passa a ser uma ação afirmativa para as mulheres. 
Por outro lado, ao observar alguns dados quantitativos sobre a participação feminina na política, ainda é possível encontrar indícios de mecanismos de dominação que, ainda hoje, mantêm a baixa participação das mulheres nas instâncias representativas da política e do poder. O fato de a população ser de maioria feminina, e os cargos políticos serem majoritariamente ocupados por homens, é um fenômeno que oferece muitas possibilidades de análise. Esse cenário foi bastante mencionado pelas prefeitas, e parece ser bastante recorrente nas discussões políticas e culturais da sociedade. Ao tentar interpretar esse fenômeno junto às prefeitas entrevistadas, elas parecem descrever uma abordagem reducionista, mesmo que não conformadas com isso, sobre a tradição e a facilidade da dominação masculina, sobre a maior capacidade masculina de atuar na política, que entende a mulher como desinteressada, menos capaz e menos envolvida nos assuntos públicos e de gestão política. Constatado esse fato, é necessário buscar as causas, os porquês desse entendimento, e quais as formas de superar essa visão de dominação. Nesse sentido, este estudo coloca-se como um passo no sentido de buscar a realidade de mulheres que se tornaram prefeitas, e, com essas vivências, entender as particularidades, os desafios, aprendizados e superações nessa carreira, tradicionalmente ocupadas por homens, mas que, gradativamente, torna-se também um espaço onde as mulheres dedicam sua vida e carreira.

Embora as prefeitas apresentem personalidades e histórias bastante distintas, foi possível identificar alguns pontos comuns nas suas falas enquanto mulheres que se tornaram prefeitas: a preocupação com a comunidade e com o fazer o bem para as pessoas, o apego à família e a importância do apoio do marido e dos filhos nas suas carreiras e o orgulho diante do pioneirismo no papel de prefeita nos seus municípios.

As prefeitas, de fato, dividem-se nos seus papéis público e privado, e se, por vezes, podem parecer excludentes, muitas vezes, têm sido utilizados como valores complementares na construção de identidades políticas estratégicas das mulheres. Assim, a presença da mulher nos espaços públicos traz novos significados tanto para a política como para as mulheres, já que o papel privado de mãe e esposa dedicada não é, necessariamente, oposto à competência administrativa, ao compromisso com a gestão pública e à firmeza necessária para atuar como chefe do executivo municipal. Pelo contrário, tem sido, muitas vezes, apresentado como mérito, como demonstrativo da capacidade feminina de gestão. 
Constatados os fatos, é necessário buscar causas, novos conhecimentos e maiores entendimentos. Conhecer os desafios femininos, seja na política ou em carreiras executivas privadas, faz-se muito importante para a superação de barreiras, de preconceitos e quebra de estereótipos sobre o feminino $\mathrm{x}$ masculino, sobre os papéis previamente determinados por capacidades, ocupações e realizações. Esse é o desafio lançado neste estudo. Embora não seja tarefa simples, é importante fazer-se cruzar as fronteiras disciplinares, percorrer técnicas e métodos que possibilitem um olhar multi e interdisciplinar para entendermos mais esses desafios das carreiras femininas. Através de conhecimento, contribui-se para a mudança da realidade.

Por fim, embora seja possível ainda verificar a persistência de traços de uma cultura baseada na divisão entre homens e mulheres em espaços de atuação de poder político, sendo as mulheres constantemente destinadas à esfera privada - de mãe, esposa, e, na política, primeira-dama - cabendo ao homem exercer as funções de poder na esfera pública, também é possível encontrar indícios de avanços significativos na atuação feminina no poder público local. A igualdade de oportunidades é também uma questão democrática, de empoderamento feminino, de inclusão social, de responsabilização pelos rumos da sociedade e eliminação de discriminação contra a mulher, tanto no âmbito da esfera privada como da pública.

\section{Referências}

ALVES, J. Paradoxos da participação política da mulher no Brasil. 2007. Disponível em <http://www.prt18.mpt.gov.br/eventos/2007/mulher/anais/artigos/jose_eustaquiopdf>. Acesso em: 20 nov.2016.

BARBOSA, C. Atuação das Mulheres na Política Local: Ranços e Avanços. Revista Ágora, Vitória, n. 11, 2010, p. 1-27.

BARBOSA, C.; CAVALCANTI, V. Um Olhar sobre a Trajetória das Prefeitas Baianas: entraves e avanços. Fazendo Gênero 9 Diásporas, Diversidades, Deslocamentos 23 a 26 de agosto de 2010. Disponível em: <http://www.fazendogenero.ufsc.br/9/resources/anais/1277462300 ARQUIVO_Fazendo_Genero.pdf>. Acesso em: 20 nov. 2016. 
BLAY, E. Mulher e igualdade: cidadania e gênero. Social Democracia Brasileira, Brasília, v.1, n. 2, p. 58-63, mar. 2002

. As prefeitas. Rio de Janeiro: Avenir, 2015.

BOTELHO, L. L. R. Ascensão Profissional Feminina em Organizações Baseadas em Conhecimento. Universidade Federal de Santa Catarina. 2008. Dissertação (Programa de PósGraduação em Engenharia e Gestão do Conhecimento) - Universidade Federal de Santa Catarina, Florianópolis, 2008.

BOTELHO, L. et al. Percepções sobre o papel da mulher na sociedade do conhecimento. In: Seminário Internacional Fazendo Gênero VII, 2006, Florianópolis. Anais Seminário Internacional Fazendo Gênero VII, 2006.

BOURDIEU, P. A dominação masculina. Rio de Janeiro: Bertrand Brasil, 2011

A representação política. Elementos para uma teoria do campo político. In: BOURDIEU, P. O poder simbólico. Lisboa: Difel, 1986.

. O sendo prático. Petrópolis: Vozes, 1980.

. Razões práticas: sobre a teoria da ação. Campinas: Papirus, 1996

BRABO, T. Gênero e poder local: eleições municipais do ano 2000 em Marília (SP). Tese (Doutorado em Sociologia, Departamento de Sociologia) - Universidade de São Paulo, 2003.

BRUSCHINI, C. Gênero e trabalho no Brasil: novas conquistas ou persistência da discriminação? (Brasil, 1985-1995). In: ROCHA, M. I. B. da (Org.) Trabalho e gênero: mudanças, permanências e desafios. São Paulo: Editora 34, 2000. p. 13-58.

BRUSCHINI, C.; LOMBARDI, M. R.; MERCADO, C. M.; RICOLD, A. Trabalho, renda e políticas sociais: avanços e desafios. In: BARSTED, L. L.; PITANGUY, J. (Orgs.). O Progresso das Mulheres no Brasil 2003-2010. Rio de Janeiro: Cepia, Brasília: ONU Mulheres, 2011.

COREDE MISSÕES. Planejamento Estratégico Corede Missões. 2012. Disponível em <http://www2.al.rs.gov.br/forumdemocratico/LinkClick.aspx?filetic ket=9 Urkjjeva2g\%3D\&tabid =5363\&mid=7972>. Acesso em: 26 set. 2016.

CUNHA, A C. C; SPANHOL, C. Liderança Feminina: características e importância à identidade da mulher. Saber Humano, ano 4, n. 5, 2014. ISSN 2178-7689.

FLETCHER, J. K. Gender perspectives on work and personal life research. Disponível em: $<w w w . p o p c e n t e r . u m d . e d u / e v e n t s /$ nichd/papers /fletcher.pdf>. 2006. Acesso em: 20 set. 2016.

GIL, A. Como elaborar projetos de pesquisa. São Paulo: Atlas, 1991. 
HUGHES, J. A filosofia da pesquisa social. Rio de Janeiro: Zahar, 1980.

MILES, M.; HUBERMAN, M. Qualitative Data Analysis. Thousand Oaks: Sage. 1994.

MINAYO, M. C. S. et al. Pesquisa social: teoria, método e criatividade. Petrópolis: Vozes, 1994.

MORAES, F. C. V. Diversidade e Inclusão: a força de trabalho feminina na Philips do Brasil. Trabalho apresentado a Fundação Dom Cabral para a conclusão do curso Gestão Responsável para a Sustentabilidade. São Paulo, 2004.

MORAES, L. V. S. A trajetória de mulheres executivas em universidades catarinenses. (Tese de Doutorado em elaboração no programa de Pós-Graduação em Engenharia de Produção) Universidade Federal de Santa Catarina, 2008.

RABAY, G. et al. As Prefeitas Paraibanas de 2013 de 2016. Seminário Internacional Fazendo Gênero 10 (Anais Eletrônicos). Florianópolis, 2013.

RODRIGUES, D. As prefeitas em perspectiva: representatividade Feminina na política paraibana. Revista Eletrônica de Ciência Política, v. 7, n. 1, 2016.

ROESCH, S. M. A. Projetos de estágio do curso de administração: guia para pesquisas, projetos, estágios e trabalhos de conclusão de curso. São Paulo: Atlas, 1996.

SEIDMAN, I. Interviewing as qualitative research: A guide for researchers in education and the social sciences (2nd ed.). New York: TeachersCollege Press, 1998.

SOUZA, P. F. de; SIQUEIRA, E. S.; BINOTTO, E. Liderança Feminina na Gestão Pública: um estudo de caso da Universidade do Estado do Rio Grande do Norte. 2011. Disponível em: <http://www.abepro.org.br/biblioteca /enegep2011_TN_STP_141_893_18429.pdf>.Acesso em: 21 set. 2016.

TER-RS. Tribunal Regional Eleitoral do Rio Grande do Sul. Eleições 2012: Divulgação dos Resultados. Disponível em: <http://www.tre-rs.jus.br/eleicoes/2012/1turno/RS87483.html>. Acesso em: 20 set. 2016.

TSE. Tribunal Superior Eleitoral. Disponível em: <http://www.tse.jus.br>. Acesso em: 20 set. 2016.

VAZ, G. A participação da mulher na política brasileira: a lei de cotas. Monografia apresentada para o curso de Especialização em Processo Legislativo. Câmara dos Deputados, 2008. 